JURNAL PENELITIAN

PERAN NINIK MAMAK DALAM PENINGKATAN PEMUNGUTAN PAJAK BUMI DAN BANGUNAN ( PBB ) DI NAGARI LANSANO TARATAK KECAMATAN SUTERA KABUPATEN PESISIR SELATAN

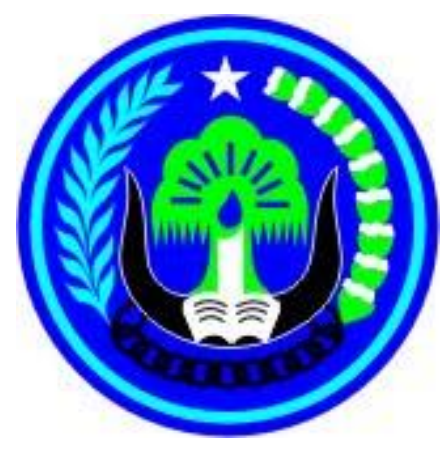

Disusun Oleh :

Sayid Anshar, SHI, MH. NIDN. 1025078102

FAKULTAS ILMU SOSIAL DAN ILMU POLITIK UNIVERSITAS EKASAKTI 


\title{
PERAN NINIK MAMAK DALAM PENINGKATAN PEMUNGUTAN PAJAK BUMI DAN BANGUNAN ( PBB ) DI NAGARI LANSANO TARATAK KECAMATAN SUTERA KABUPATEN PESISIR SELATAN
}

\author{
Sayid Anshar, SHI, MH. \\ Email ancasaid14@gmail.com
}

\begin{abstract}
ABSTRAK
Masalah dalam penelitian ini adalah Bagaimana Peranan Ninik Mamak Dalam Peningkatan Pemungutan Pajak Bumi Dan Bangunan Di Nagari Lansano Taratak Kecamatan Sutera Kabupaten Pesisir Selatan. Tujuan penelitian ini adalah untuk mengetahui seberapa besar, Peranan Ninik Mamak Dalam Peningkatan Pemungutan Pajak Bumi Dan Bangunan Di Nagari Lansano Taratak Kecamatan Sutera Kabupaten Pesisir Selatan.

Penelitian ini dilaksanakan di Kenagarian Lansano Taratak Kecamatan Sutera Kabupaten Pesisir Selatan dan yang menjadi populasi dalam seluruh Perangkat Nagari dan Masyarakat Nagari di Kenagarian Kenagarian Lansano Taratak Kecamatan Sutera beserta Masyarakat Oleh karena itu yang menjadi sampel dalam penelitian ini adalah Masyarakat Nagari,seluruh petugas pemungut pajak dan Ninik Mamak yang ada dalam Pemerintahan Nagari LansanoTaratak Kecamatan Sutera Kabupaten Pesisir Selatan yang berjumlah 15 orang. Sampel diambil dengan Proportional Cluster Random Sampling dengan menggunakan rumus slovin, dengan jumlah sample sebanyak 5 orang.

Teknik pengumpulan data adalah dengan menggunakan wawancara. Untuk melihat Peranan Ninik Mamak Dalam Peningkatan Pemungutan Pajak Bumi Dan Bangunan Di Nagari Lansano Taratak Kecamatan Sutera Kabupaten Pesisir Selatan.

Berdasarkan hasil penelitian disarankan diharapkan Ninik Mamak hendaknya lebih giat dalam memberikan masukan kepada kaumnya akan penting pajak bumi dan bangunan dan Melakukan sosialisasi kepada masyarakat tentang pentingnya membayar pajak.
\end{abstract}

Kata Kunci : Peranan, Pajak Bumi dan Bangunan 


\begin{abstract}
The problem in this study is how the role of Ninik Mamak in increasing land and building tax collection in Nagari Lansano Taratak, Sutera District, Pesisir Selatan Regency. The purpose of this study was to determine how much, the Role of Ninik Mamak in Increasing Land and Building Tax Collection in Nagari Lansano Taratak, Sutera District, Pesisir Selatan Regency.

This research was carried out in Kenagarian Lansano Taratak, Sutera Subdistrict, Pesisir Selatan Regency and which became the population in all Nagari Devices and Nagari Communities in the Kenagarian Lansagari Kenagarian Sutera District, Sutera District and the Community. Therefore, the samples in this study were the Nagari Community, all tax collectors and Ninik Mamak who is in Nagari LansanoTaratak Government, Sutera Subdistrict, Pesisir Selatan Regency, amounting to 15 people. Samples were taken by Proportional Cluster Random Sampling using the Slovin formula, with a total sample of 5 people.

Data collection technique is to use interviews. To see the Role of Ninik Mamak in Increasing Land and Building Tax Collection in Nagari Lansano Taratak, Sutera District, Pesisir Selatan Regency. Based on the results of the study it was suggested that Ninik Mamak was expected to be more active in providing input to his people on the importance of land and building taxes and to socialize to the public about the importance of paying taxes.
\end{abstract}

Keywords: Role, Land and Building Tax

\title{
A. PENDAHULUAN
}

\subsection{Latar Belakang Masalah}

Pajak merupakan potensi yang harus terus digali dalam menambah penerimaan daerah dikarenakan obyek pajak ini adalah bumi dan bangunan yang jelas sebagian besar masyarakat memilikinya. Hanya saja pemungutan PBB sering kali mendapatkan hambatan, baik mulai dari sosialisasi kepada masyarakat yang kurang, pemahaman masyarakat yang sempit mengenai pajak sampai pada metode pemungutannya yang kurang efektif dan efisien dan lain sebagainya. 
Melalui Peran ninik mamak atau pemimpin adat dalam Nagari baik di dalam kaumnya sendiri, di dalam masyarakat dalam peningkatan pajak bumi dan bangunan sangatlah penting. Sebagai ninik mamak dia adalah suatu lembaga tertinggi di dalam adat di setiap Nagari di minangkabau,Ninik mamak ini akan dapat membujuk anak kemanakannya untuk taat akan pajak demi kemajuan pemabangunan Nagari. Maka dari itu seorang ninik mamak sebagai pemimpin di dalam kaumnya haruslah bertugas: Menyuarakan agar anak kemenakan yang dipimpinnya mau patuh akan membayar pajak. Selain itu peran Ninik Mamak dalam pemerintahan Nagari sangat lah penting terutama dalam upaya peningkatan pajak bumi dan bangunan,karena Ninik mamak ini sebagai penghubung dalam menyampaikan segala persoalan dan aspirasi anak kemanakan ke Pemerintahan Nagari.Tanpa dukungan dari Ninik Mamak masyarakat akan enggan mengeluarkan pajak bumi dan bangunan.Hal ini membuktikan keterkaitan kedua belah pihak.

Berdasarkan latar belakan diatas, maka menarik untuk dilakukan penelitian tentang “ Peran Ninik Mamak Dalam Peningkatan Pemungutan Pajak Bumi Dan Bangunan ( PBB ) Di Nagari Lansano Taratak Kecamatan Sutera kabupaten Pesisir Selatan"

\subsection{Rumusan Masalah}

Berdasarkan rumusan masalah diatas, maka penulis merumuskan masalah penelitian sebagai berikut : Bagaimana Peranan Ninik Mamak Dalam Peningkatan Pemungutan Pajak Bumi Dan Bangunan Di Nagari Lansano Taratak Kecamatan Sutera Kabupaten Pesisir Selatan?

\section{Tujuan Penelitian}

Tujuan Penelitian ini adalah : untuk mengetahui Peranan Ninik Mamak Dalam Peningkatan Pemungutan Pajak Bumi Dan Bangunan Di Nagari Lansano Taratak Kecamatan Sutera Kabupaten Pesisir Selatan. 


\section{B. KAJIAN PUSTAKA}

\subsection{Pengertian Peranan}

Peranan berasal dari kata peran.Peran memiliki makna yaitu seperangkat tingkat diharapkan yang dimiliki oleh yang berkedudukan di masyarakat.(Kamus Besar Bahasa Indonesia.Peranan adalah bagian dari tugas utama yang harus dilaksanakan".Peranan merupakan aspek yang dinamis dari kedudukan (status) Apabila seseorang yang melakukan hak dan kewajiban sesuai dengan kedudukannya, maka dia menjalankan suatu peranan mencakup kewajiban hak yang bertalian kedudukan".Peranan adalah suatu aspek dinamika berupa pola tindakan baik yang abstrak maupun yang kongkrit dan setiap status yang ada dalam organisasi mengemukakan peranan adalah terciptanya serangkaian tingkah laku yang saling berkaitan yang dilakukan dalam suatu situasi tertentu serta berhubungan dengan kemajuan perubahan tingkah laku.

Berdasarkan pendapat diatas dapat disimpulkan bahwa peranan adalah suatu pola tindakan yang dilakukan oleh aparat desa baik secara individual maupun secara bersama-sama yang dapat menimbulkan suatu peristiwa. Analisis terhadap perilaku peranan dapat dilakukan melalui tiga pendekatan : (1)ketentuan peranan, (2) gambaran peranan, dan (3) harapan peranan. Ketentuan peranan adalah pernyataan formal dan terbuka tentang perilaku yang harus ditampilkan oleh seseorang dalam membawa perannya.

\subsection{Ninik Mamak di Minangkabau}

Mamak adalah saudara laki-laki dari pihak ibu. Semua saudara lakilaki ibu baik adik maupun kakaknya yang sudah dewasa menikah disebut mamak. Secara khusus mamak bukanlah sekedar saudara laki-laki ibu akan tetapi mamak adalah seorang yang dituakan dan dianggap cakap dan bertanggung jawab terhadap kelangsungan sistim matrineal di Minangkabau. Di dalam kehidupan masyarakat Minangkabau laki-laki memilki dua fungsi yaitu sebagai kepala keluarga/rumah tangga ( tunganai) dan sebagai mamak artinya laki-laki itu juga menjadi pemimpin dari adik-adik dan kemanakannya. Sebagai seorang 
mamak ia diaharapkan mengawasi adik dan kemanakannya yang perempuan serta mengurus dalam hal-hal yang berhubungan dengan tata cara bernagari atau bermasyarakat.

Peranan Ninik Mamak merupakan korps atau kesatuan dari kepemimpinan tradisional Minangkabau yang terdiri dari para Panghulu atau kepemimpinan kaum yang bergelar datuk, Secara fungsional ninik mamak merupakan salah satu unsur dari tungku tigo sajarangan.Keberadaannya sangat mempengaruhi pelaksanaan kontrol sosial terhadap masyarakat. kontribusi ninik mamak dalam pembangunan masyarakat nagari sebagai kolektivitas atau terhimpun dalam sebuah organisasi KAN/LAN. Akan saya bahas terlebih dahulu perjalanan organisasi ninik mamak ini.Himpunan ninik mamakdalam sebuah organisasi pada tingkat nagari merupakan tradisi Minangkabau semenjak lama. Organisasi mereka yang semenjak lama ada disebut Kerapatan Adat Nagari (KAN). Para peneliti mengatakan KAN tersebut telah dikenal pada zaman Kolonial Belanda, walaupun tidak secara resmi diakui oleh pemerintah kolonial tersebut. Ketika di provinsi ini diterapkan Undang-undang Pemerintahan Desa No. 5/1979 dengan mengubah pemerintahan nagari ke pemerintahan desa, pada tahun 1983 pemerintah Provinsi Sumatera Barat mengukuhkan KAN sebagai organisasi ninik mamak pada tingkat nagari dan diberi tugas mengelola nagari sebagai komunitas hukum adat. Organisasi ninik mamak pada tingkat nagari terus diakui oleh negara ketika di Provinsi Sumatera Barat sistem pemerintahan terbawah ditukar dari desa ke nagari. Pemerintah kabupaten, kemudian, menerapkan nama yang berbeda terhadap organisasi ini (ada yang menyebut Kerapatan Adat Nagari, KAN, dan ada pula yang menyebut Lembaga Adat Nagari, LAN).

\subsection{Pengertian Pajak}

Pajak merupakan salah satu sumber penerimaan Negara yang digunakan untuk melaksanakan pembangunan bagi seluruh rakyat Indonesia. Pajak dipungut dari warga Negara Indonesia dan menjadi salah satu kewajiban 
yang dapat dipaksakan penagihannya.Pembangunan nasional Indonesia pada dasarnya dilakukan oleh masyarakat bersama-sama pemerintah.Oleh karena itu peran masyarakat dalam pembiayaan pembangunan harus terus ditumbuhkan dengan meningkatkan kesadaran masyarakat tentang kewajibannya membayar pajak.Pajak merupakan alternatif yang sangat potensial.Sebagai salah satu sumber penerimaan Negara yang sangat potensial, sektor pajak merupakan pilihan yang sangat tepat, selain karena jumlahnya yang relatif stabil juga merupakan cerminan partisipasi aktif masyarakat dalam membiayai pembangunan.

Jenis pajak daerah sebagaimana yang ada dalam Undang-Undang nomor 28 tahun 2009 adalah Pajak Kendaraan Bermotor; Bea Balik Nama Kendaraan Bermotor; Pajak Bahan Bakar Kendaraan Bermotor; Pajak Air Permukaan; dan Pajak Rokok; Pajak Hotel; Pajak Restoran; Pajak Hiburan; Pajak Reklame; Pajak Penerangan Jalan; Pajak Mineral Bukan Logam dan Batuan; Pajak Parkir; Pajak Air Tanah; Pajak Sarang Burung Walet; Pajak Bumi dan Bangunan Perdesaan dan Perkotaan; Bea Perolehan Hak atas Tanah dan Bangunan Perlu diketahui bahwa sistem pemungutan pajak ada 3 (tiga) macam yaitu Official Assessment System, Self Assessment System, With Holding System.Official Assessment System adalah system pemungutan pajak yang memberi wewenang pemerintah (fiskus) untuk menentukan besarnya pajak yang terutang oleh Wajib Pajak.Self Assessment System adalah system pemungutan pajak yang memberi wewenang kepada Wajib Pajak untuk menentukan sendiri besarnya pajak yang terutang dan With Holding System adalah system pemungutan pajak yang memberi wewenang kepada pihak ketiga (bukan fiskus atau Wajib Pajak yang bersangkutan) untuk menentukan besarnya pajak yang terutang oleh Wajib Pajak. Indonesia menganut Self Assessment System yaitu Wajib Pajak diberi kepercayaan untuk menghitung, memperhitungkan, menetapkan, membayar, dan melaporkan pajaknya sendiri. Fiskus, dalam hal ini aparat Direktorat Jendral Pajak/ Pemerintah Daerah hanya menjalankan fungsi 
pembinaan, penelitian, pengawasan, dan penerapan sanksi administrasi perpajakan.

\section{METODE PENELITIAN}

\subsection{Metode Yang Digunakan}

Menurut Sugiono, metode penelitian adalah cara ilmiah yang digunakan untuk mendapatkan data dengan tujuan tertentu. Lebih jelas lagi dijelaskan oleh Bogdan dan Taylor sebagaimana dikutip oleh Lexi. J. Moleong, metodologi kualitatif sebagai prosedur penelitian yang mengumpulkan data deskriptif berupa kata-kata tertulis atau lisan dari orang-orang dan perilaku yang dapat diamati, Metode yang yang digunakan dalam penelitian ini adalah dengan menggunakan pendekatan kualitatif ,yaitu penelitian yang bersifat deskriptif, kualitatif karena penelitian ini mendeskripsikan yang telah terjadi dengan cara mencatat, menganalisis dan menginterprestasikan kondisi-kondisi yang telah terjadi.

\subsection{Populasi dan Sampel}

a. Populasi

Menurut Cholid Narbuko dan Abu Ahmadi, populasi adalah wilayah generalisasi yang terdiri atas objek atau subjek yang mempunyai kualitas dan karakteristik tertentu yang ditettapkan dalam penelitian untuk dipelajari dan kemudian ditarik kesimpulan.

b. Sampel

Marzuki memberikan batasannya yang menyatakan bahwa sampel adalah bagian dari populasi yang tidak dapat dipisahkan dengan yang lain. Menurut Soekidjo sampel adalah sebagian untuk diambil dari keseluruhan obyek yang diteliti dan dianggap mewakili seluruh populasi. Dalam pengambilan sampel ini peneliti menggunakan metode pemilihan berdasarkan tujuan ( Purposive Sampling ). yang menjadi sampel dalam penelitian ini 
adalah 5 orang terdiri dari 1 orang Wali Nagari Lansano Taratak ,2 orang Ninik Mamak , 1 petugas pajak Bumi Bangunan,dan 1 orang masyarakat.

\subsection{Teknik Pengumpulan Data}

a. Studi Kepustakaan

Data yang bersifat teori,penulis peroleh melalui buku-buku dan jurnaljurnal yang berhubungan dengan masalah-masalah yang dibahas dan bukubuku lain yang menunjang penyelesaian penelitian ini.

b. Studi Lapangan

1. Observasi

Kegiatan yang dilakukan dalam pengamatan ini adalah mencari dan memahami situasi objek penelitian yang berkaitan dengan peranan Ninik Mamak Dalam Peningkatan Pemungutan Pajak Bumi Dan Bangunan Di Nagari Lansano Taratak Kecamatan Sutera.

2. Wawancara

Pengumpulan data melalui wawancara dengan Tokoh Masyarakat, pemangku adat ,bagaimana Peranan Ninik Mamak Dalam Peningkatan Pemungutan Pajak Bumi Dan Bangunan Di Nagari Lansano Taratak Kecamatan Sutera

\subsection{Sumber Data}

1. Data primer

Yaitu data yang diperoleh langsung di lapangan melalui penyebaran angket kepada masyarakat mengenai Peranan Ninik Mamak Dalam Peningkatan Pemungutan Pajak Bumi Dan Bangunan Di Nagari Lansano Taratak Kecamatan Sutera

2. Data Sekunder

Yaitu data yang diperoleh melalui studi kepustakaan maupun dokumentasi serta catatan-catatan yang relevan dan berhubungan dengan penelitian yang peneliti lakukan 


\subsection{Analisa Data}

Setelah data penelitian dikumpulkan kemudian analisis yang akan digunakan untuk menjawab pertanyaan penelitian adalah menggunakan anlisis Deskriptif. Analisis ini bertujuan menggambarkan apa yang ditemukan pada hasil penelitian ini dan memberikan informasi sesuai dengan apa yang diperoleh di lapangan dengan menyampaikan dalam bentuk penyatuan data ke dalam bentuk hasil distribusi frekuensi, kemudian dilakukan analisis persentase mean standar deviasi, tingkat capaian responden, dan koefisien serta memberikan interprestasi analisis tersebut.

\section{HASIL PENELITIAN DAN PEMBAHASAN}

\section{Peranan Ninik Mamak Dalam Peningkatan Pemungutan Pajak Bumi Dan Bangunan Di Nagari Lansano Taratak Kecamatan Sutera Kabupaten Pesisir Selatan.}

Keberadaan Ninik Mamak di Kenagarian Lansano Taratak Kecamatan Sutera Kabupaten Pesisir Selatan, selaku pemangku adat tertinggi di kaumnya berharap agar ninik mamak di nagari bisa berfungsi, terutama untuk menjalankan aturan adat di Nagari terutama masalah pajak bumi dan bangunan serta bertanggung jawab penuh terhadap kemanakan dan pesukuan masing-masing dari niniak mamak tersebut. Sebagai Ninik mamak seharusnya menjaga, memelihara serta bertanggug jawab terhadap kaum yang dipimpinnya.Apapun masalah yang timbul dalam kaum, ninik mamak lah yang turun tangan untuk menyelesaikannya. Karena ninik mamak itu adalah tumpuan bagi kaum mereka, peran ninik mamak di Nagari sangat perlu digalakkan lagi, agar apapun permasalahan yang timbul di Nagari benar-benar bisa diselesaikan dengan adat Minangkabau. Bukan hanya peran niniak mamak atau pemangku adat tetapi Walinagari selaku pemimpin secara adat dan administasi di Nagari, dituntut harus jeli terhadap perubahan yang terjadi Nagari yang dipimpinnya itu. Walinagari mencermati perilaku budaya warganya, berperan aktif di Nagari demi menjaga keharmonisan kaum 
adat.( Hal ini disampiakan oleh bapak Nofrizal selaku warga kenagarian Lansano Taratak.

Pada kesempatan ini penulis melakukan wawancara dengan Salah seorang Ninik mamak Nagari Lansano Taratak Kecamatan Sutera yang bernama Nofrizal dia menjelaskan tentang Peranan Ninik Mamak Dalam Peningkatan Pemungutan Pajak Bumi Dan Bangunan Di Nagari Lansano Taratak Kecamatan Sutera Kabupaten Pesisir Selatan pajak bumi dan bangunan diantaranya :

1) Ninik mamak memiliki peranan memberikan motivasi kepada masyarakat terutama kepada anak kemanakannya.

Motivasi yang diberikan oleh ninik mamak kepada masyarkat akan berdampak positif bagi kelancaran pemungutan pajak bumi dan bangunan,hal ini disebabkan karena ninik mamak memiliki peranan penting dalam kehidupan bermasyarkat di Nagari

2) Ninik mamak dapat melakukan pembinaan dan sosialisasi kepada masyarkat akan pentingnya pajak bumi dan bangunan.

Ninik mamak sangat berpengaruh dalam kehidupan bernagari,karena Ninik Mamak merupakan tokoh panutan dalam masyrakat yang lebih di tuakan dalam kaumnya,dalam hal ini ninik mamak akan dapat melakukan pembinaan dan sosialisasi kepada masyrakat akan pentingnya pajak bumi dan bangunan bagi kelancaran pembangunan di Nagari Taratak Lansano Kecamatan Sutera.

3) Ninik Mamak memiliki peranan yang dapat membantu petugas pemungut pajak dalam melakukan pemugutan pajak.

Hubungan yang sinergi antara Ninik mamak dengan petugas pemungut pajak bumi dan bangunan akan berdampak kepada kelancaran proses pemungutan pajak ,Dalam hal ini ninik mamak memiliki peranan yang dapat menjalin hubungan yang baik dengan petugas pemungut pajak bumi dimana ninik bisa meyakinkan masyarakat akan pentingnya pajak bumi dan bangunan ,sehingga nantinya tidak terjadi kesalah pahaman antara masyarakat dengan petugas pemungut pajak. 
Salah satu penerimaan Nagari Lansano Taratak yang saat ini sedang gencar-gencarnya digalakkan adalah pajak bumi bangunan .Pajak merupakan peralihan kekayaan dari sektor swasta ke sektor publik berdasarkan Undangundang yang dapat dipaksakan dengan tidak mendapat imbalan yang secara langsung dapat ditunjukkan yang sangat penting bagi pelaksanaan dan peningkatan pembangunan nasional sebagai pengamalan pancasila yang bertujuan untuk meningkatkan kemakmuran dan kesejahteraan rakyat, dan oleh karena itu perlu dikelola baik dari segi pemungutan maupun dari segi administrasi pengelolaan dan petugas pemungut pajak tersebut.

Salah satu bentuk pajak yang dipungut oleh Pemerintahan Nagari Lansano Taratak adalah Pajak Bumi dan Bangunan (PBB). Pajak Bumi dan Bangunan merupakan salah satu jenis pajak yang hasil penerimaannya disumbangkan kepada Pemerintah Nagari. PBB pengelolaannya diserahkan kepada Direktorat Jenderal Pajak dengan unit operasionalnya adalah Kantor Pelayanan Pajak Bumi dan Bangunan (KPPBB). Pajak Bumi dan Bangunan adalah pajak langsung, sehingga pemungutannya langsung kepada wajib pajak, dan saat terutangnya pada awal tahun berikutnya. Pajak Bumi dan Bangunan merupakan pajak objektif, sehingga obyek pajaknya berupa tanah dan atau bangunan menentukan terutang pajak atau tidak.

berdasarkan hasil wawancara dengan masyarakat Lansano Taratak, bapak Nofrizal, menjelaskan Peranan Ninik Mamak Dalam Peningkatan Pemungutan Pajak Bumi Dan Bangunan Di Nagari Lansano Taratak Kecamatan Sutera Kabupaten Pesisir Selatan memiliki peranan strategis dalam meningkatkan penerimaan Nagari. Hal yang mendasar dan yang sangat penting dalam penarikan Pajak Bumi dan Bangunan yang dilakukan oleh pemungut pajak di Pemerintahan Nagari Lansano Taratak Kecamatan Sutera adalah bahwa dalam melaksanakan tugas-tugasnya, Nagari membutuhkan biaya yang sangat besar dalam rangka mensukseskan pembangunan yang telah berjalan. Untuk mendapatkan biaya tersebut dapat ditempuh dengan berbagai jalur, antara lain dengan penarikan 
pajak bumi dan bangunan. Pajak ini merupakan potensi yang harus terus digali dalam menambah penerimaan Nagari dikarenakan obyek pajak ini adalah bumi dan bangunan yang jelas sebagian besar masyarakat memilikinya. Hanya saja pemungutan PBB sering kali mendapatkan hambatan, baik mulai dari sosialisasi kepada masyarakat yang kurang, pemahaman masyarakat yang sempit mengenai pajak sampai pada metode pemungutannya yang kurang efektif dan efisien dan lain sebagainya.

Peranan ninik Mamak dalam meningkatkan pajak bumi dan bangunan di Nagari Lansano Taratak Kecamatan Sutera menurut Isap DT.Rj.Malenggang dimana ia menyimpulkan bahwa :

1. Ninik Mamak mempunyai kedudukan yang lebih tinggi dibanding jabatan lainnya yang ada dalam masyarakat dalam menyemangati kaumnya agar senantiasa patuh dan taat dalam pembayaran pajak bumi dan bangunan

2. Ninik Mamak dalam pemerintahan Nagari memiliki peran dalam pembangunan nagari

3. Sebagai tempat dalam penyelesaian konflik pajak bumi dan bangunan.

4. Merupakan tempat sandaran dan tempat bertanya tentang berbagai permasalahan yang dihadapi warga masalah pajak bumi dan bangunan.

5. Kepemimpinan Ninik Mamak itu samping arif bijaksana, la juga harus pintar memilah-milah di antara sekian banyak kasus yang terjadi di kalangan anak kamanakan atau masyarakatnya. la akan mengambil suatu keputusan yang bijak, masuk akal dan menyenangkan dengan ukuran-ukuran (norma) yang umum

\section{E. PENUTUP}

\subsection{Kesimpulan}

Berdasarkan hasil wawancara penulis bahwa Peranan Ninik Mamak Dalam Peningkatan Pemungutan Pajak Bumi Dan Bangunan Di Nagari Lansano Taratak Kecamatan Sutera Kabupaten Pesisir Selatan memiliki peranan 
strategis dalam meningkatkan penerimaan Nagari. Hal yang mendasar dan yang sangat penting dalam penarikan Pajak Bumi dan Bangunan yang dilakukan oleh pemungut pajak di Pemerintahan Nagari Lansano Taratak Kecamatan Sutera adalah bahwa dalam melaksanakan tugas-tugasnya, Nagari membutuhkan biaya yang sangat besar dalam rangka mensukseskan pembangunan yang telah berjalan. Untuk mendapatkan biaya tersebut dapat ditempuh dengan berbagai jalur, antara lain dengan penarikan pajak bumi dan bangunan.

\section{F. DAFTAR PUSTAKA}

AstridS. Susanto, 1979, Pengantar Sosiologi dan Perubahan Sosial,Bandung, BinaCipta.

Brotodiharjo, Santoso. Pengantar Ilmu Hukum Pajak. Bandung: PT Refika

Hadikusuma Hilman,. 1992, Pengantar Ilmu Hukum Adat Indonesia. Bandung, Penerbit Mandar Maju

Rosmeli, 1995, Peranan Normatif Mamak di Ujung Rantau Minangkabau, Pekanbaru

Rochmat Soemitro, Prof.Dr.H.S.H., dan Zainal Muttaqin, S.H., 2001, Pajak Bumi dan Bangunan, Bandung. (edisi revisi) PT Refika Aditama.

Soebroto, R.., 1980, Pokok-pokok Pengertian Ilmu Taha Usaha, Jakarta, Balai Pembinaan Administrasi, Akademi Administrasi Negara 
